\title{
Póster-Innovación* \\ CONTAMINACIÓN EN EL HOGAR. APLICACIÓN EN EL AULA
}

Gordo Antoñana, Blanca, Juárez Navas, Ana Ma , Lupión Cobos, Teresa y Puerta Cirre, J. Miguel. Coordinadora Teresa Lupión Cobos (IES Ciudad Jardín, Málaga)

\section{INTRODUCCIÓN}

En el desarrollo de la programación de la asignatura Ciencia, Técnica y Sociedad nuestro grupo pone en práctica la unidad CONTAMINACIÓN (1) dentro del bloque temático «Repercusiones sociales del desarrollo científico-tecnológico. Aplicaciones concretas» (2). Esta unidad consta de los siguientes capítulos: CONTAMINACIÓN ATMOSFÉRICA, DEL AGUA, RADIACTIVA, ACÚSTICA y EN EL HOGAR, la cual aquí describimos.

\section{DESARROLLO DEL TEMA}

Primera fase: exploración de ideas previas a modo introductorio y motivador. Así se realiza una encuesta sobre compra, uso, composición, impacto ambiental, etc. (Anexo I), a diferentes grupos sociales, categorizando las respuestas en orden a razones de sexo, edad, estudios. El diseño, realización y análisis de la correspondiente estadística aproxima al alumno al desarrollo de contenidos interdisciplinares paralelos de interés. Asimismo nos permite abordar objetivos específicos de la unidad de tipo conceptual, procedimental y actitudinal, como concepto de detergente, contaminación, eutrofización, funciones del lavado, etc.; incorporación e integración de datos y/o vocabulario científico, utilización de fuentes de información diversa, realización de representaciones gráficas que reflejen correctamente la información recopilada, respeto al medio ambiente, entre otras.

Segunda fase: el profesor combina estrategias de exposición y de descubrimiento o indagación, presenta un informe donde recoge todos los conceptos a estudiar con la propuesta de actividades de desarrollo (Anexo II) en las que el intercambio de ideas y las argumentaciones aportadas en el aula constituyen un objetivo en sí mismas, y a su vez sustentan la consecución de otros. Los debates, las informaciones variadas y secuenciadas, aportadas tanto por el profesor como por los alumnos, son herramientas didácticas que dan importantes resultados, promoviéndose así la reconstrucción personal de su conocimiento.

Se alternan el trabajo en pequeños grupos y el trabajo individual con exposiciones del profesor siendo su labor la de moderar, orientar, guiar, corregir o completar la exposición de los alumnos, favoreciendo la interacción entre éstos y el trabajo en equipo.

La evaluación se fundamenta en la valoración de los cuestionarios, cuaderno de clase, informes y observación del trabajo diario, así como de los proyectos o pequeñas investigaciones realizados por el alumno.

\section{CONCLUSIONES}

- La secuenciación de las tareas propuestas les ha facilitado la asimilación de los contenidos tratados, tal y como ellos mismos comentan, valorando especialmente la metodología aplicada.

- La realización de actividades iniciales ha sido altamente motivadora, asimismo, les ha permitido abordar conocimientos de otras materias del curriculum, alcanzando así objetivos interdisciplinares genéricos, inherentes a esta asignatura. Así objetivos de especial relevancia procedimental, como diseño de gráficos, elaboración de diagramas, se alcanzan.

- La aplicación de diferentes tareas les ha dotado de una mayor solidez argumentativa, desarrollando su espíritu crítico, consiguiendo conclusiones valorativas aplicadas a su entorno próximo.

\section{REFERENCIAS BIBLIOGRÁFICAS}

1. BOYANO, J.T., GORDO, B., LUPIÓN, T., PUERTA, J.M. y RUIZ, M.L. (1997). «La Contaminación. Una propuesta didáctica para la asignatura CTS». Ed. los autores.

2. G.T. GALILEO. (2000). «Experiencias del Grupo de trabajo Galileo en el entorno CTS». XIX Encuentros en Didáctica CCEE. Univ. Comp. de Madrid.

\section{ANEXOS}

I. 1. ¿Se deja llevar por la publicidad a la hora de comprar un producto de limpieza?. 2. ¿Le preocupa la contaminación que puede producir? ¿Lo usa correctamente y sigue las instrucciones del envase? 3. Si se entera de que un determinado producto contamina, ¿procura sustituirlo por otro que no lo haga ? 4. Ordene por importancia : eficacia, económico, muy conocido por la publicidad, ecológico. 5. ¿Qué clase de información necesita al comprar? 6. ¿Puede existir peligro al mezclar distintos productos?.

II. 1. Cumplimentación de cuestionarios sobre: $a$ ) búsqueda de términos científicos, $b$ ) etiquetas de productos de limpieza doméstica. 2. Elaboración de cuadros de composición química y de su relación precio - calidad - contaminación. 3. Realización de pequeños informes sobre documentos aportados por el profesor. 4. Preparación de pequeñas investigaciones con información obtenida a través de diferentes portales vía Internet.

* Este póster, por error, no apareció publicado en el Tomo 2 del volumen extra correspondiente al VI Congreso Internacional sobre Investigación en la Didáctica de las Ciencias, por lo cual se incluye en este número de Enseñanza de las Ciencias. 